\title{
A ruptura intergeracional em situação migratória. Questão de autoridade, olhar dos filhos sobre seu pai e sobre a paternidade.
}

La rupture intergenerationnelle en situation migratoire. Question d'autorité, regard des enfants sur leur père et paternité.

Inter-generation rupture in a migratory situation. The issue of authority, the children's view of their father and of paternity.

La ruptura intergeneracional en una situación migratoria. La cuestión de la autoridad, la mirada de los hijos hacia su padre y hacia la paternidad.

Edwige Rude-Antoine*

Resumo

Este artigo analisa, com base em entrevistas semidiretivas com jovens filhos de imigrantes, a sua relação com os pais e, em especial, a questão da paternidade. Os resultados mostram que, pelo fato de serem imigrantes ou exilados, os pais encontram dificuldades em integrar outras concepções sobre suas prerrogativas. Eles são confrontados com novos significantes relativos a seu papel, o que pode gerar, para alguns deles, perturbaçóes psíquicas. Os filhos têm problemas para reconstituir a ordem geracional de suas famílias, enquanto os pais negam o fato de serem imigrantes, além de denegar sua origem. Seu exílio e suas inserções na sociedade francesa podem acentuar neles o sentimento de não terem outra identidade senão a de trabalhadores, além de não serem reconhecidos pelos próprios filhos. Existe, pois, uma verdadeira ruptura intergeracional entre esses pais, que aparecem como destituídos de sua função paterna, e seus filhos.

Palavras-chave: pais imigrados; conflito de papéis; ruptura intergeracional; perda da função paterna.

\section{Resume}

Cet article analyse, à partir d'entretiens semi-directifs réalisés auprès de jeunes issus de l'immigration, leur relation avec leurs pères et plus particulièrement la question de la paternité. Les résultats montrent que du fait de leur exil, les pères rencontrent des difficultés à intégrer d'autres conceptions des prérogatives parentales. Ils sont confrontés à

\footnotetext{
Texto recebido em junho de 2009 e aprovado para publicação em setembro de 2009.

Jurista, socióloga e psicanalista, diretora de Pesquisa do Cerses - Centre de Recherche Sens, Éthique, Société, Université Paris-Descartes, CNRS, UMR 8137, e-mail: edwige.rude-antoine@parisdescartes.fr.
} 
de nouveaux signifiants, concernant leur rôle et qui peuvent générer, chez certains d'entre eux, des perturbations psychiques. Les enfants ont du mal à reconstituer l'ordre générationnel de leurs familles, pendant que les pères dénient leur acte de migrer et leur origine. Leur exil et leur insertion dans la société française peuvent accentuer leur sentiment de n'avoir d'autre identité que celle de travailleurs et de ne pas être reconnus par leurs propres enfants. Il existe alors une véritable rupture intergénérationnelle entre ces pères, qui apparaissent comme destitués de leur fonction paternelle, et leurs enfants.

Mots-clé: parents imigrés; conflit de rôles; rupture intergénérationnelle; perte de la fonction paternnelle

\section{Abstract}

Based on semi-directive interviews with immigrants' young children, this article analyzes their relations with the parents, especially the issue of paternity. Results point out that, as the parents are immigrants or exiled, they find it difficult to integrate other conceptions concerning their prerogatives. They are confronted with new meanings related to their role, which can generate, for some of them, psychic disorders. The children have problems in reconstructing their families' generation framework, while the parents deny the fact that they are immigrants, besides denying their own origin. Exile and insertion into French society can emphasize their feeling of not having an identity other than that of workers, and of not being recognized by their own children. There is, therefore, a real inter-generation rupture between those parents, who seem deprived of their paternal role, and their children.

Key words: Immigrated parents; Role conflict; Intergeneration rupture; Loss of paternal role.

\section{Resumen}

Este artículo analiza, basado en las entrevistas semi-directivas a jóvenes hijos de inmigrantes, la relación con los padres y, especialmente, la cuestión de la paternidad. Los resultados muestran que, por el hecho de ser inmigrantes o exiliados, los padres encuentran dificultades en integrar otras concepciones a sus prerrogativas. Se enfrentan a nuevos significantes relativos a su rol, lo que puede generar, en algunos de ellos, perturbaciones psíquicas. Los hijos tienen problemas para reconstituir el orden generacional de sus familias, mientras que los padres niegan el hecho de ser inmigrantes, además de negar su origen. Su exilio y su integración en la sociedad francesa pueden acentuar un sentimiento de que no tienen otra identidad, que no sea la de trabajadores/operarios, además de que no son reconocidos por sus propios hijos. Existe, pues, 
una verdadera ruptura intergeneracional entre esos padres, que aparecen como destituidos de su función paterna, y la de sus hijos.

Palabras-clave: padres inmigrados; conflicto de roles; ruptura intergeneracional; pérdida de la función paterna.

\section{Introdução}

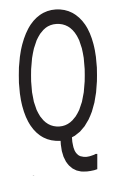

uem quer que se interesse pelas questões migratórias nas sociedades contemporâneas constata que as questões pesquisadas, muitas vezes, tratam das modalidades de aproximação do imigrante à norma: desaparecimento progressivo das práticas culturais específicas (Tribalat, 1995), campos da vida social sensíveis à aculturação por oposição a um "núcleo duro cultural" (Schnapper, 1991), identificação das condições que explicam o domínio do sistema de valores tradicional sobre as segundas gerações, ou, ao contrário, sua predisposição a se afastarem deles (Tribalat, 2001, p. 64-71). São também os valores expressos pelas minorias como afirmações identitárias (Oriol, 1984) ou como expressões de etnicidade no sentido anglo-saxão (Poutignat \& Streiff-Fénart, 1999) que estão no seio dos questionamentos. Sob essa ótica, enfatizam-se as relações dinâmicas entre os grupos, não propriamente seus traços culturais substanciais. As maneiras de fazer, os modos de vida são assim articulados, levando-se em conta a dramaturgia social da imigração: fantasia da traição, fechamento identitário, etc. A questão das crianças migrantes é tratada tendo em vista a proteção delas. Estejam elas acompanhadas, que sejam menores isolados que vêm "se juntar", errantes ou fugitivos explorados, as pesquisas (Schiff, 2002; Barou \& Moro, 2003; Groupe d'Information et de Soutien des Immigrés, 2002; Diminescu, 2004) mostram a variedade de perfis, as motivaçôes, assim como os dispositivos e os tratamentos que lhes são especialmente destinados, desde a polícia de fronteiras até sua escolarização, passando pelo juizado de menores ou pelo alojamento em abrigos.

Neste artigo, gostaríamos de retomar os resultados de uma pesquisa (Rude-Antoine, 1997) que nos havia sido encomendada pelo Ministério da Justiça francês com o objetivo de analisar a incidência dos fatores culturais na construção identitária dos jovens e em seus processos de socialização. A investigação se referia também à execução de práticas educativas ditas “inovadoras", que levam em conta a dimensão cultural e, mais particularmente, as práticas da nova etnopsiquiatria. Esta propõe às instituições, bem como aos profissionais do campo social e do campo jurídico que trabalham junto a famílias e jovens oriundos da imigração, uma compreensão de seus 
problemas, ao relacioná-los ao sentido que se supõe ser o da cultura de seu país. Mas a pesquisa evidenciou os riscos dessas práticas que interpretam os distanciamentos de comportamentos dos imigrantes com relação a sua cultura de origem. Os fatores culturais não pareceram ser preponderantes para compreender as trajetórias dos jovens migrantes. Por outro lado, o lugar dos pais e a questão da paternidade, tema que diz respeito, ao mesmo tempo, à subjetividade, como teorizou Lacan (1966), e ao campo social, apareceram como um problema para esses jovens colocados em algum abrigo ou serviço de ação educativa em meio aberto ou até mesmo em um centro educativo ou profissional. Quando esses jovens falam de seus pais, do que estão falando? Em que a ruptura com um ambiente, uma terra, a ruptura com um espaço instituído por uma representação pode levar a consequências diversas?

Em nossas pesquisas, realizamos narrativas de vida de jovens que haviam imigrado com a família, quando ainda eram crianças de pouca idade, ou que vieram mais tardiamente juntar-se a um ou vários membros da família. Desses jovens, somente dois tinham nascido na França, de pais estrangeiros. Alguns deles tinham sido atores na ruptura com seu país, com o campo antropológico do grupo de pertencimento. Esses jovens, todos institucionalizados, manifestavam distúrbios do comportamento. A maioria deles havia cometido algum ato delituoso. Assim, comparamos essas narrativas com as de um grupo-testemunha de jovens nascidos na França de pais franceses, também institucionalizados. Todos tinham entre 15 e 21 anos e desvelaram fatos marcantes de suas trajetórias individuais e familiares. Também fizemos entrevistas semidirigidas tanto com pais e mães quanto com trabalhadores sociais das diferentes instituições.

Segundo as narrativas de vida recolhidas, a história desses jovens começa nos bairros de periferia em que vivem. Sejam eles oriundos de uma vila da Tunísia, sejam berberes do Marrocos, sejam de uma vila na Costa do Marfim ou de qualquer outro lugar, eles se dizem, antes de tudo, descendentes de um imigrante que veio trazer sua contribuição à economia de um país antigamente colonizador. Aliás, isso lembra o famoso estudo sobre o imigrante como única força de trabalho, desenvolvido por Sayad (1991), que insistia na dimensão social da vergonha e na questão da desqualificação social.

O que também marca o observador com relação a esses jovens é que eles pertencem a famílias em que as solidariedades coletivas foram rompidas. Seus pais não pertencem, em sua maioria, a nenhuma associação compatriota. Não houve, como no caso de outras migraçôes, um reagrupamento de famílias deslocadas de uma mesma vila. Eles estão ali naquele bairro pobre, dispersos em meio aos outros imigrantes. Eles não têm um lugar no espaço coletivo, 
menos ainda no espaço comunitário. Eles são somente jovens do bairro pobre, de pais imigrantes, que também não investiram o lugar, o território, como princípio estruturante.

Nesta pesquisa, podia-se observar sua exigência de palavra desses jovens, dirigida a seus pais, assim como sua maneira de designar o pai, ao se referirem à mãe. Os jovens diziam não se entenderem mais com seus pais, sobretudo com o pai. Eles falavam de uma quebra, de uma ruptura intergeracional.

Os trabalhadores sociais insistiam em falar sobre a falha da função paterna, ao ponto em que podíamos nos perguntar se ainda havia um "pai" para esses jovens. Nosso trabalho teórico se insere em um questionamento mais vasto. Com efeito, o que significava, no contexto desses jovens que viveram ou apenas herdaram a experiência do exílio, a figura de um "pai"? Os trabalhadores sociais pareciam falar desses pais "deslocados" como de uma evidência que não carecia de teorização, mas, para o pesquisador, havia toda uma diversidade de terminologia a respeito dos pais: a posição do pai, a função do pai, o papel do pai, a carência do papel do pai, pais em dificuldade e um conjunto de propósitos de especialistas sobre essa questão evidenciando, em nossas sociedades sem pai (Mitscherlich, 1963), o declínio da imagem paterna (Tellenbach, 1976), pais que se tornaram mães sem lugar específico (Naouri, 1985).

$\mathrm{O}$ que nos interessava neste trabalho de pesquisa, bem mais do que a dinâmica de mudança em situação de imigração, introduzida pelos sociólogos para falar das mudanças devidas ao fato migratório, era levar em conta os comportamentos desses pais em relação à ruptura com sua sociedade de origem, com todas as consequências intrapsíquicas para eles próprios e para as gerações seguintes. $\mathrm{O}$ que esses jovens podem fazer com sua história e com a história de seus pais? Como é que eles podem se moldar, como podem construir "pais" ou o "pai"?

\section{A paternidade em exílio: entre normatividade e problemática do sujeito}

$\mathrm{Na}$ França, originalmente, o pai representava o mestre, ou seja, o dirigente da cidade. A paternidade era política e religiosa, ela só era familiar por via de consequência. $\mathrm{Na}$ época feudal, o pai era caracterizado por alguns tipos de relações sociais, algumas formas e funções da família e do casamento, que encontraram seu apogeu nos séculos X e XI. Mais tarde, com o novo fundamento da sociedade sendo a fraternidade e não mais a paternidade, depois da execução de Luís XVI e sob a influência do ideal burguês do século 
XIX, a autoridade paterna foi centrada exclusivamente na família. Segundo Julien,

[...] o patris potestas é somente o poder de ter uma mulher e, com isso, ter filhos. Daí a força do adágio jurídico Pater est quem nuptia demonstrandum, que pode ser traduzido por "o pai é aquele designado pelas núpcias". Assim, o filho tem como pai o marido de sua mãe. $\mathrm{O}$ direito de paternidade sobre a criança não é mais baseado no poder político e religioso, mas em uma ligação anterior, a conjugalidade (Julien, 1991, p. 16).

Mais tarde, o conceito de conjugalidade seria substituído pelo de parentalidade. A conjugalidade, conceito oriundo da cristianização do direito romano e que fundou nossa ordem social durante muito tempo, tornou-se então precário, pelo fato de que o casamento passou a ser pensado na esfera privada de cada casal como princípio organizador do espaço social da família (Théry, 1996).

Assim, o pai do século XIX não era o dos anos 1950 nem o de hoje. Nos anos 1950, a lei jurídica mencionava o "pátrio poder". Só 20 anos depois, com a lei de 4 de junho de 1970, essa noção foi substituída pela de "poder familiar". Com a lei Malhuret, de 22 de julho de 1987, que emenda a lei de 1970, o juiz tem a faculdade de decidir que o poder familiar será exercido em comum, após o divórcio, e abre essa possibilidade aos pais naturais. Em seguida, a lei de 8 de janeiro de 1993 coloca como regra geral a possibilidade do exercício em comum do poder familiar pelos dois pais, o juiz só intervém para fixar a residência habitual da criança. O exercício do poder familiar por um só dos dois pais se torna a exceção da regra geral, no caso em que o interesse da criança exija que seja assim. A lei confere aos pais naturais a possibilidade de exercerem em conjunto o poder familiar (Art. 374, al. 3, da Lei de 8 de fevereiro de 1995) se ambos os pais reconheceram o filho antes que ele tenha atingido a idade de um ano e vivem juntos no momento do reconhecimento concomitante ou do segundo reconhecimento. Caso contrário, a lei prevê que o poder familiar é exercido pela mãe, mas que ele pode ser exercido pelos dois pais, se eles fizerem um requerimento conjunto, diante do oficial de justiça chefe do tribunal de grande instância, ou se um deles fizer esse requerimento judicialmente.

Mais recentemente, a lei de 4 de março de 2002, relativa ao poder familiar, reafirma claramente o exercício conjunto do poder familiar, com relação aos filhos, conforme a Lei n ${ }^{\circ} 2002-305$ de 4 de março de 2002, relativa ao poder familiar (France, 2002). 
Surge uma questão a respeito das consequências, para os pais, dessas mutações jurídicas: como é que esses pais em situação de imigração podem basear-se em outros sistemas jurídicos, em matéria de autoridade? Matérias como poder paterno, direito de guarda do filho pela mãe, até determinada idade, obrigação de sustento do filho por parte do pai, etc. Elas podem integrar outras concepções das prerrogativas paternas que estão longe das suas?

No trabalho social, o encontro entre os pais em exílio e os profissionais se articula em torno de um conjunto de representações sobre o que devem ser as relações entre pais e filhos, sobre a maneira de interpretar os direitos e os deveres dos pais. Ora, como escreve Jodelet (1989), as representaçōes "engajam o pertencimento [...] dos indivíduos às implicaçóes afetivas e normativas, às interiorizações de experiências, de práticas, de modelos de conduta e de pensamento, socialmente inculcados ou transmitidos pela comunicação social e ligados a esse pertencimento" (Jodelet, 1989, p. 36). A questão que se coloca é a de saber em que termos e em que sentido esses pais representam sua experiência do direito do poder familiar e nele se inspiram na organização de sua vida cotidiana.

Não é possível ignorar que a especificidade de uma cultura jurídica é também a dos valores veiculados por uma tradição cultural. Ao longo de nossa pesquisa, constatamos que não é mais dado a esses pais, tendo em vista o processo de "desculturação" galopante em que eles vivem, opor um conhecimento ativo dos fundamentos de suas tradiçõos jurídicas. Na maior parte das vezes, eles vivem simultaneamente dois universos de pensamento, ambos dotados de certa coerência interna, mas eles não têm as ferramentas que lhes permitiriam traduzir a experiência de uma das culturas nos termos da "outra" cultura. Não será a primeira vez que seremos levados a constatar uma ruptura muito clara entre as representações que os pais fazem de suas prerrogativas paternas e das de seus filhos, que cresceram ou estão crescendo em outro universo sociocultural.

O conceito de pai é, muitas vezes, apresentado como uma realidade simples, conhecida logo de cara, já que se refere a uma experiência: seu próprio pai, sua própria paternidade. No entanto, a literatura dedicada a essa questão da paternidade mostrou toda a sua complexidade. Valérie Colin-Simard (2003), em seu ensaio Père d'aujourd'hui, filles de demain, mostra a importância das relações entre pai e filha. Outro ensaio sociojurídico, Des vies et des familles, les immigrés, la loi et la coutume (Rude-Antoine, 1997a), trata dos movimentos migratórios e de suas consequências sobre o modo de ocupar o lugar de pai e mãe. Da mesma forma, a pesquisa coletiva Autorité et immigration, realizada pelo Institut des Hautes Études et de la Sécurité Intérieure (1997), analisa os vetores da autoridade nos diversos contextos sociojurídicos e culturais. 
Como Lacan escreveu muito justamente, "a paternidade, como a maternidade, têm uma essência problemática - são termos que não se situam puramente ou simplesmente no nível da experiência” (Lacan, 1981, p. 201).

O pai é o fruto de uma ficção, de uma suposição, de uma conjectura, escrevia Sigmund Freud, mas ele também é aquele que é colocado no lugar de ser assim designado, por uma mulher, pelo dispositivo jurídico, pelo código social ou pelo próprio filho, ou mais exatamente pelas relações dos sujeitos implicados pela lei. O pai não é um homem de qualidade, ainda que superior, mas pelo pai age e opera a qualidade, na medida em que ele exerce uma função, e em qualidade de, com o título de pai, o que não poderia existir sem a palavra (Clerget, 1992, p. 65).

Em outros termos, cada sociedade designa uma pessoa para carregar o nome de pai. Daí, define-se para essa pessoa um papel de pai, ou seja, o conjunto de condutas concretas que ela deve manifestar, ligadas, por um lado, às leis que definem seus direitos e seus deveres (em relação ao que é legitimamente esperado de um pai de família e pela sociedade) e ligadas, por outro lado, às imagens e aos ideais sociais (Segalen, 1981). Enfim, pelo fato dessa nomeação como pai, essa pessoa deverá encarnar a função paterna que é da ordem da linguagem, que introduz sentido por um sujeito que é estruturado por aquilo que os psicanalistas chamam de complexo de Édipo. Assim, a função paterna é caracterizada por uma dupla inscrição no campo social e no campo da subjetividade.

\section{A inscrição social da função paterna}

No campo social, a função paterna se inscreve por meio de montagens jurídicas. Para Héritier (1985, p. 237) "cada sociedade, enquanto grupo de seres humanos, funciona nesses campos do parentesco, conforme um uso coerente que lhes é próprio e que é a lei do grupo". Trata-se das leis referentes à filiação, à genealogia, à aliança, ao parentesco, e que constituem suas bases fundadoras. Em nome da lei, cada sociedade designa quem é o pai e quais são os homens que vão ocupar esse lugar. Há um termo, um significante para marcar o lugar simbólico do pai.

No sistema jurídico francês, os critérios legais de designação do pai variaram. Dois foram usados: a verdade biológica e a vontade, segundo a qual um homem que não é o genitor pode ser designado como pai. Existem duas formas de filiação: "uma delas é baseada no biológico e a outra, adotiva, 
repousa em uma presunção afetiva, em que o direito cria artificialmente entre uma pessoa que o requer e outra pessoa uma relação de pai (ou/e de mãe) com a criança”" (Rude-Antoine, 1999, p. 18). Não é prioritariamente o real da semeadura que é levado em conta, mas as leis que designam quem é o genitor. Como disse Lacan, em sua palestra para os alunos da Columbia University em 1974, "o pai é uma função que se refere ao real, que não é, forçosamente, o verdadeiro do real". Todavia alguns esclarecimentos são necessários, pois, com as novas tecnologias, verificações a respeito do "real" do genitor se tornaram possíveis e permitem uma oscilação entre o critério biológico e o critério legal. Com efeito, é possível constatar uma filiação duvidosa, buscar uma verdade biológica, descobrir a verdade sobre um parto anônimo. Nesses casos, quem se impõe é a natureza, e não a sociedade, para designar o pai.

Nessa designação da pessoa do pai, o que está em jogo não é somente o fato jurídico, é também o conjunto das representaçôes a ele associadas. $\mathrm{O}$ papel de pai genitor ou individual, muito próximo da mulher e dos filhos, tal como conhecemos na França, não é universal.

Em alguns países da África, por exemplo, o importante não reside no fato de ser "o pai de", mas de ser "o filho de", inscrevendo o sujeito de direito em uma estrutura relacional, que induz o reconhecimento do princípio da hierarquia, perceptível na relação assim instaurada do filho mais novo ao mais velho. Por causa disso, vários autores podem concorrer à paternidade: há o pai genitor, o pai social ou o pai jurídico (expressão tirada do Código de Família do antigo Zaire, hoje República Democrática do Congo). Há uma distinção a ser feita entre a responsabilidade da concepção e a responsabilidade na representação jurídica, com relação a terceiros. A questão da paternidade está, portanto, ligada a uma questão de filiação "de quem sou filho?", e a resposta deve ser buscada em sua linhagem, e não no indivíduo, como na França. Nas sociedades matrilineares, as inscrições na linhagem materna são privilegiadas, há automaticamente uma dissociação entre a paternidade biológica e a paternidade social assumida pelo irmão da mãe (ou tio materno). Nas sociedades patrilineares, o pai biológico pode ser o pai social. A transmissão das funções de representação do grupo pode associar a função paterna a um status de representante de um grupo mais vasto, no qual se inscreve a unidade familiar de procriação. Como enfatiza muito bem Étienne Le Roy, antropólogo do direito,

[...] para os Wolof, o pai social é o borom keur, chefe da casa, ainda que o pai biológico seja o borom diébot, chefe da família restrita. A transmissão do status pode ser feita verticalmente (de pai para filho) ou horizontalmente (de irmão mais velho para irmão caçula) para esgotar a linha e mudar de geração. Todos esses representantes 
potenciais da comunidade familiar são "pais" a títulos diversos. A terminologia de parentesco os designa, qualificando o lugar (pai "o grande", pai "o pequeno", por exemplo, para especificar o mais velho e o mais novo), e, por conseguinte, suas funçôes (Le Roy, 1998, p. 72-73).

No Magreb, outro exemplo, a figura do pai é a de um pai protegido, não sujeito aos desafios. Fethi Benslama \& Gilbert Grandguillaume (1989) precisam que o pai é referido a uma figura ancestral, sem por isso ser confundido com ela. Ele é voltado para o passado, para uma filiação ascendente e não dirigida a seus filhos. Seu lugar é único, herdado, não pode ser tomado antes de sua morte e, enquanto ele estiver vivo, nenhum de seus filhos pode usar o título de pai diante dele. Com esse pai de referência, que é a afirmação da patrilinearidade, no nível simbólico do fundador, as rivalidades, os conflitos não são possíveis. Enquanto o pai de referência estiver presente, os outros só são pais de modo contingente, ou seja, pais individuais, no sentido de que o que os designa assim depende da condição imanente de terem gerado filhos. O pai de referência é o princípio encarnado da paternidade e de sua autoridade na família.

Assim, esses pais no exílio se veem confrontados a exigências sociais do "papel" do pai na sociedade de chegada, que nem sempre correspondem às do "papel do pai" na sociedade de partida. As figuras do pai que correspondem a seus países de origem cedem seu lugar a um pai que vai conhecer a incerteza inerente ao pai genitor ou individual. Uma ruptura se opera com a figura do pai tradicional, na qual o pai é mais um pai grupal (da linhagem) do que um pai individual, e pode gerar nesses pais exilados formas de ansiedade ou até mesmo perturbações psíquicas.

Como escreve Lacan, "O homem está, desde antes de seu nascimento e além de sua morte, tomado na corrente simbólica, a qual fundou a linhagem, antes que a história fosse ali abordada" (Lacan, 1966, p. 468). Cada sociedade fabrica um pai para o filho, ou seja, ela o refere aos desafios da linhagem e da genealogia (Legendre, 1996). Ora, as narrativas recolhidas por nós mostram que os jovens estão impossibilitados de reconstituir a ordem geracional de suas famílias. Uma jovem, Sonia, não tem nenhuma referência da linhagem paterna que ficou na Argélia. Ela se inscreve mais na genealogia de sua mãe. Ela diz:

Por parte da minha mãe, minha avó teve sete filhos. Tenho um tio, Denis, ele tem 45 anos e dois filhos. O outro, Patrick, tem cinco filhos, e o menor deve ter uns 4 anos. Os dois são casados. Além deles, tenho um outro tio. Depois, há a minha tia Danièle, 
ela tem um menininho, ela tem 37, 38 anos, ela é casada. Depois, há minha mãe, que tem 38 anos, então somos três filhos. E minha tia Sylvie, 35, 36 anos, ela tem duas filhas e um filho, com 12, 10 e 8 anos. Eu me encontro muito com eles. Por parte de meu pai, não conheço todos os meus tios e tias. Só conheço uns três ou quatro que estão na França. Na Argélia, meu pai não manteve nenhum laço (Sonia).

Da mesma forma, Mohamed lembra os laços distendidos com sua linhagem paterna. Ele explica que a história familiar não foi contada, que seu pai não fala da vida em seu país:

$\mathrm{Na}$ França, meu pai tem sua irmã. Na Argélia, eles desapareceram (silêncio). Meu pai nem procura saber. Às vezes, eles escrevem. $\mathrm{O}$ filho do irmão dele mandou uma foto, mas ele não quer responder. Ele não quer nem saber (Mohamed).

Muitas vezes, esses jovens só têm alguns vestígios de sua genealogia. Por parte de pai, eles só se lembram de alguns organizadores significativos que podem operar como "um princípio ativo de pertencimento" (Certeau, 1984).

Os jovens contam todas as suas tentativas para que seus pais os situem com relação a sua história familiar e pessoal. Mas eles deparam uma verdadeira negação, pelo fato de que o pai tem dificuldades em relembrar sua vida no país de origem, mas também em contar seu ato de migrar. Pois esses pais carregam "essa ausência sempre suspeita" da qual Sayad (1991) fala tão bem, isto é, a falta original que é consubstancial ao ato de emigrar. Atores da ruptura com o grupo de pertencimento, esses pais carregam uma fantasia de ilegitimidade. Eles podem viver seu exílio como uma indignidade, uma maldição ou até mesmo como uma queda infinita que nunca chega a lugar algum. Por isso, os jovens são confrontados a um bloco imaginário desconhecido e a uma ruptura com a temporalidade. Eles, muitas vezes, não têm meios de elaborar a maneira singular de situar-se em uma linhagem.

\section{A inscrição subjetiva da função paterna}

No campo da subjetividade, a função paterna se inscreve em cada sujeito por meio das montagens familiares. O complexo de Édipo é a estrutura que, para cada sujeito, estabelece que há um pai como representante da Lei (Lacan, 1966). De Sigmund Freud a Jacques Lacan, o que se destaca como estrutura 
constituinte do sujeito é o complexo de Édipo. Ele é formado em seu centro pela imago do pai e pelas funções dessa imago. Sua função essencial é a proibição da mãe. A lei primordial é aquela que, ao regular a aliança, superpõe o reino da cultura ao reino da natureza, à mercê da lei do acoplamento (Lacan, 1966). Esse psicanalista acrescenta que a proibição do incesto é o pivô subjetivo da lei. O pai é o garantidor do interdito do incesto, o terceiro separador da mãe. O pai, como destaca Françoise Héritier, é quem garante a legitimidade da afiliação das crianças do grupo (Héritier, 1985). Portanto, a criança pertence a uma família, no sentido de um parentesco no qual, antes mesmo de seu nascimento, é -lhe preparado um lugar que se pode qualificar de simbólico (um sobrenome) e imaginário (desejo dos pais).

Para que a criança possa se constituir como sujeito, alguém deve encarnar e assumir a função simbólica do pai. Anne, da Costa do Marfim, que adquiriu a nacionalidade francesa aos 13 anos, por adoção, conta como seu padrasto encarnou e assumiu essa função:

$\mathrm{Na}$ verdade, ele não é meu pai (genitor). Ele me reconheceu ao se casar com minha mãe. E eu não tinha pai. Eu passei a vida inteira sem ter um pai. Primeiro foi difícil, mas, quando eu ganhei meu pai, foi maravilhoso. Era um sonho! Eu sempre desejei ter um pai. Eu logo me liguei a ele, para mim ele era meu pai, ainda que eu não tenha tido um pai antes. Deus tinha me dado um pai, eu estava feliz. Eu vim, eu estava realmente feliz, e foi aqui que tudo começou. Aos treze anos ... (Anne).

Anne (Costa do Marfim) insiste em sua narrativa em falar de seu sobrenome, que, no passado, a inscreve em um lugar simbólico incestuoso:

Nós fomos ao tribunal, ele contratou um advogado, fomos à prefeitura, ele pegou uma certidão de nascimento e depois passamos na embaixada da Costa do Marfim, o país onde eu nasci. Foi assim que eu me tornei francesa, por meu pai. No meu país, a gente tem o sobrenome do pai. Eu tinha o sobrenome do meu avô materno. Eu mudei de sobrenome. Eu só mudei o sobrenome. Foi aqui que tudo começou (Anne).

Ela não insiste no nome patronímico enquanto tal, mas realmente no significante que representa a lei em um sujeito. É a partir desse significante, importante para ela, que o mundo de Anne vai organizar-se: nesse "foi aqui que tudo começou", precisa ela, continuando sua narrativa, ela começou a se sentir sujeito, que pôde sair de si mesma, que pôde existir. Todo o seu discurso é situado com relação a esse momento, seja antes ou depois. Assim, a paternidade não se caracteriza pelo fato de ser o pai fecundante, mas pela função inscrita nas leis e transmitida a um sujeito com força de Lei, situando-o em um lugar definido no seio de um sistema de parentesco. 
É no seio da família, com relações familiares objetiváveis, relações interpessoais, mas também com relações intersubjetivas, de palavra e de linguagem, que o sujeito, a criança, situa-se como tal. No lugar em que a presença simbólica do pai traz problemas, o sentido e a lei trarão sintomas. Segundo Lacan, para que o ser humano fique marcado com a função do "Nome do pai", é preciso que, para sua mãe, esse lugar simbólico exista. Se esse lugar está forcluído para ela, ele também o estará para a criança. Da mesma forma, é necessário que o pai testemunhe que ele também está, como homem, marcado pela lei, ou seja, que ele é falível e desejante.

Ora, esses pais no exílio, como observa Sayad, muitas vezes, "não têm outra identidade além da de trabalhador e não têm outra existência real além da que o trabalho lhes confere" (Sayad, 1994, p. 45). Quando estão desempregados, como testemunham as narrativas de vida desses jovens, a palavra dos pais não tem mais o mesmo peso. Vejamos um trecho da narrativa de Ezzedine, sobre seu pai:

Ele era operário na Citroën e foi demitido em 1994. E agora ele é operário temporário por contrato. A demissão dele foi difícil para mim, inclusive agora. Antes, eu não sabia. Mas eu gostaria que ele tivesse um emprego, porque o que me deixa chateado é que ele não trabalha, ele está sempre lá em casa. Às vezes, gostaríamos de comprar isso ou aquilo, mas temos dificuldades financeiras e muitos projetos não podem ser realizados (Ezzedine).

Essa ausência do pai na esfera profissional, ou até mesmo na esfera social, leva a questionar o modo de presença autorizado ao imigrante, a presença que o imigrante realiza na imigração, sua maneira de ser ausente, os efeitos de sua ausência, o fato de que os pais sempre permanecem sendo emigrados de algum outro lugar. Para seus filhos, o trabalho fundamenta a presença de seus pais no território francês e sua ausência do país de partida. As mães já não fazem muito caso das palavras dos pais. Os trabalhadores sociais destacam, aliás, que o domicílio familiar já não é mais, nessas famílias, o domicílio do pai e da mãe, mas o da mãe e do filho mais velho, que acaba sustentando as necessidades da família com sua renda obtida de maneira mais ou menos legal.

\section{Considerações finais}

A nova lei sobre o poder familiar não pode, evidentemente, pretender resolver todos os problemas da crise das famílias e da "desagregação" das responsabilidades dos pais. Mas ela tem o mérito de equalizar a condição 
da criança e de atribuir mais importância às decisões dos pais. No caso de determinados pais exilados, ela não resolve essa ruptura que os filhos vivem com seus pais. Ela destaca as divergências de representação de uns e outros a respeito do que devem ser as relações entre pais e filhos e o lugar da autoridade na família. Os pais em exílio têm o sentimento de que seus filhos lhes escapam, em decorrência de suas referências culturais, diferentes das referências profissionais. Suas atitudes de retração descritas por seus filhos não resultam, ao que parece, de uma escolha deliberada, mas do sentimento de que não são reconhecidos nessa sociedade em que residem. A sociedade civil intervém cada vez mais junto às famílias em dificuldade, em nome de um suposto saber sobre seu bem-estar. É o papel dos pedopsiquiatras, dos psicólogos, dos professores, dos trabalhadores sociais, definir o que permitirá o crescimento da criança. Ora, a análise dos dados coletados mostra que esses profissionais, muitas vezes, fazem um amálgama entre a realidade da presença do pai na família, caracterizada por determinados modos de comportamentos (presença ou ausência física, violência, alcoolismo, etc.) e a realidade da presença do pai para um sujeito. Os pais em exílio percebem os especialistas das questóes familiares, cujo trabalho é suprir as lacunas educativas, como pessoas que têm suas próprias teorias, seus próprios valores, às vezes em contradição umas com as outras. Os profissionais devem zelar para que esses discursos psicossociais não transponham esses pais para um universo abstrato demais, onde eles correriam o risco de perder o sentido particular de sua existência.

\section{Referências}

Barou, J. \& Moro, M. R. (2003). Les enfants de l'exil, étude auprès des familles en demande d'asile dans les centres d'accueil. Paris: UNICEF/Sonacotra.

Benslama, F. \& Grandguillaume, G. (1989). Transformation de la figure du père et fonction paternelle. In: Le Père - métaphore paternelle et fonctions du père: linterdit, la filiation et la transmission. Paris: Denoël, L'espace analytique.

Certeau, M. (1984). L'école de la diversité. Annales ESC, 789-816.

Clerget, J. (1992). Places des pères, violence, paternité. In: J. \& M. P. Clerget. Places du père, violence et paternité. Presses Universitaires de Lyon.

Colin-Simard, V. (2003). Père d'aujourd'hui, filles de demain. Paris: Anne Carrière. 
Diminescu, D. (2004). La mobilité des jeunes roumains à l'heure de l'élargissement européen Enfants sans frontières. Hommes et Migrations, 1251, 42-50.

France. (2002, Mars 5). Loi "Segolene Royal" n. 2002-305 du 4 mars 2002 relative à l'autorité parentale. Journal Officiel, 54, 4161.

Groupe d'Information et de Soutien des Immigrés. (2002). Rapport statistique $\mathrm{du}$ HCR sur les mineurs isolés demandeurs d'asile en Europe. Plein Droit, $\mathrm{n}^{\circ}$ 52, 3-49.

Héritier, F. (1985). Don et utilisation de sperme et d'ovocytes: Mères de substitution: un point de vue fondé sur l'anthropologie sociale. L'Homme, ${ }^{\circ}$ 94, 5-22.

Institut des Hautes Études et de la Sécurité Intérieure. (1997). Autorité et immigration. Collection Études et Recherches. Paris: IHESI.

Jodelet, D. (1989). Représentations sociales: un domaine en expansion. In: D. Jodelet (org.). Les représentations sociales. Paris: Presses Universitaires de France.

Julien, P. (1991). Le manteau de Noé. Essai sur la paternité. Paris: Desclée de Brouwer.

Lacan, J. (1981). Séminaire III - Les psychoses. Paris: Seuil.

Lacan, J. (1966). Écrits. Paris: Seuil.

Le Roy, E. (1998). Brèves considérations sur la question de la paternité dans les sociétés d'Afrique noire. Cahier La paternité, 7, 72-73.

Legendre, p. (1996). L’inestimable objet de la transmission - Leçons 4. Paris: Fayard.

Mitsherlich, A. (1969). Vers la société sans père. Paris: Gallimard.

Naouri, A. (1985). Une place pour le Père. Paris: Seuil.

Oriol. M. (org.) (1984). Les variations de l'identité. Nice: Ideric.

Poutignat, p. \& Streiff-Fénart, J. (1999). Théories de l'ethnicité. Paris: Presses Universitaires de France. 
Rude-Antoine, E. (1999). Adopter un enfant étranger. Paris: O. Jacob.

Rude-Antoine, E. (1997a). Des vies et des familles, les immigrés, la loi et la coutume. Paris: O. Jacob.

Rude-Antoine, E. (org.). (1997). Les jeunes issus de l'immigration pris en charge par la protection judiciaire de la jeunesse: trajectoires individuelles et diversité culturelle. Paris: Ministère de la Justice.

Sayad, A. (1991). L'immigration et les paradoxes de l'altérité. Paris: Éditions Universitaires.

Sayad, A. (1994). Le mode de génération des générations immigrées. Migrants Formation, n $^{\circ}$ 98, p. 6-20.

Schiff, C. (2002). Les jeunes primo-migrants: un rapport à la société distinct de celui des minorités ethniques. VEI-enjeux, (131), 222-231.

Schnapper, D. (1991). La France de l'intégration: sociologie de la nation en 1990. Paris, Gallimard.

Segalen, M. (1981). Sociologie de la famille. Paris: A. Colin.

Tellenbach, H. (1983). L'image du Père dans le mythe et dans l'histoire. Paris: Presses Universitaires de France.

Théry, I. (1996). Le remariage. Paris: O. Jacob.

Tribalat, M. (1995). Faire France: une enquête sur les immigrés et leurs enfants. Paris: La Découverte.

Tribalat, M. (2001). La transmission des valeurs traditionnelles. Informations sociales, $89,64-71$. 